\title{
Londrina Activities of Daily Living Protocol: Reproducibility, Validity, and Reference Values in Physically Independent Adults Age 50 Years and Older
}

\author{
Thaís Paes MSc, Letícia Fernandes Belo PT, Diego Rodrigues da Silva PT, \\ Andrea Akemi Morita MSc, Leila Donária MSc, Karina Couto Furlanetto MSc, \\ Thaís Sant'Anna PhD, Fabio Pitta PhD, and Nidia Aparecida Hernandes PhD
}

\begin{abstract}
BACKGROUND: It is important to assess activities of daily living (ADL) in older adults due to impairment of independence and quality of life. However, there is no objective and standardized protocol available to assess this outcome. Thus, the aim of this study was to verify the reproducibility and validity of a new protocol for ADL assessment applied in physically independent adults age $\geq 50 \mathrm{y}$, the Londrina ADL protocol, and to establish an equation to predict reference values of the Londrina ADL protocol. METHODS: Ninety-three physically independent adults age $\mathbf{2 5 0} \mathrm{y}$ had their performance in ADL evaluated by registering the time spent to conclude the protocol. The protocol was performed twice. The 6-min walk test, which assesses functional exercise capacity, was used as a validation criterion. A multiple linear regression model was applied, including anthropometric and demographic variables that correlated with the protocol, to establish an equation to predict the protocol's reference values. RESULTS: In general, the protocol was reproducible (intraclass correlation coefficient 0.91 ). The average difference between the first and second protocol was $5.3 \%$. The new protocol was valid to assess ADL performance in the studied subjects, presenting a moderate correlation with the 6-min walk test $(r=-0.53)$. The time spent to perform the protocol correlated significantly with age $(r=0.45)$ but neither with weight $(r=-0.17)$ nor with height $(r=-0.17)$. A model of stepwise multiple regression including sex and age showed that age was the only determinant factor to the Londrina ADL protocol, explaining $21 \%(P<.001)$ of its variability. The derived reference equation was: Londrina ADL $\operatorname{protocol}_{\text {pred }}(\mathrm{s})=135.618+(3.102 \times$ age $[\mathrm{y}])$. CONCLUSIONS: The Londrina ADL protocol was reproducible and valid in physically independent adults age $\geq 50 \mathrm{y}$. A reference equation for the protocol was established including only age as an independent variable $\left(r^{2}=0.21\right)$, allowing a better interpretation of the protocol's results in clinical practice. Key words: age; motor activity; activities of daily living; reproducibility of results; validation studies; reference values. [Respir Care 2017;62(3):298-306. (C) 2017 Daedalus Enterprises]
\end{abstract}

\section{Introduction}

Life expectancy worldwide has increased significantly in recent years; thus, society has been facing the conse-

\footnotetext{
The authors are affiliated with the Laboratory of Research in Respiratory Physiotherapy, Department of Physiotherapy, State University of Londrina, Londrina, Brazil.

Ms Paes was supported by the Coordination for the Improvement of Higher Education Personnel (CAPES), Brazil. Dr Pitta was supported by the National Council of Technological and Scientific Development (CNPq), Brazil. The authors have disclosed no conflicts of interest.
}

quences of aging. Changes related to the aging process, such as impairments of balance, mobility, and muscle strength, interfere in the performance of activities of daily living (ADL). These changes lead to loss of independence

\footnotetext{
Correspondence: Nidia A Hernandes PhD, Departamento de Fisioterapia, Universidade Estadual de Londrina, Avenida Robert Koch, 60-Vila Operária, 86038-350-Londrina, Paraná, Brazil. E-mail: nyhernandes@gmail.com.
}

DOI: $10.4187 /$ respcare. 05059 
and poor quality of life. ${ }^{1,2}$ Therefore, the assessment of $\mathrm{ADL}$ is of the utmost importance in this population.

The use of questionnaires is an option to assess functional status (ie, the capacity to perform ADL). However, functional status when reported by the individual might be influenced by psychological or cognitive factors. ${ }^{3}$ Another option is to perform a functional test (eg, sit-to-stand test ${ }^{4}$ or timed up-and-go ${ }^{5}$ ). Such tests have been associated with poor outcomes, such as hospitalization and mortality. ${ }^{6,7}$ Furthermore, these tests require only a few minutes and are easy to perform. There are batteries composed of functional tests, as the short physical performance battery ${ }^{8}$ and the senior fitness test. ${ }^{9}$ Although recognized as functional tests, they do not include a number of specific daily activities, mainly those that involve the upper limbs. In addition, functional tests assess the capacity to perform ADL and do not fully reflect real-life activities, since subjects are required to perform the test as fast as possible instead of at the usual ADL pace. Moreover, there is another test that also proposes to assess the capacity to perform ADL, the physical performance test. ${ }^{10}$ It is composed of 9 activities, including simulating eating, putting on and taking off a jacket, and climbing stairs. The activities are performed separately, and at the end, a total score is calculated. Despite including different activities of daily living, this protocol has some limitations, including the lack of standardization (eg, the number of stairs is not well established) and the fact that simulation of activities can lead the assessed individuals to perform them in a manner different from real daily life, leading to biased results.

Considering the limitations of the available tools used to assess ADL, a new protocol was developed by our research group, the Londrina ADL protocol. The protocol is composed of 5 activities, including walking with and without the addition of extra weight to the body, moving objects on shelves and on a table, and hanging clothes on a clothesline. The activities are performed in a circuit, and the time spent to complete the protocol is registered as an outcome. Initially, the Londrina ADL protocol was created to assess patients with COPD. However, it may also be reasonable to consider it for assessing other populations, such as the elderly; thus, it is necessary to test the measurement properties of the protocol in this population. In addition, the establishment of reference values for the Londrina ADL protocol is required to allow interpretation of the results when applied in subjects with any functional impairment. Therefore, the aims of the present study were to investigate the reproducibility and validity of the Londrina ADL protocol in physically independent adults age $\geq 50 \mathrm{y}$ and to establish an equation to predict reference values for the Londrina ADL protocol in this population.

\section{QUICK LOOK}

\section{Current knowledge}

Changes related to the aging process, such as impairments of balance, mobility, and muscle strength, interfere in the performance of activities of daily living (ADL). These changes lead to loss of independence and poor quality of life. Therefore, it is important to evaluate activities of daily living using a standardized protocol that includes the activities carried out in the daily lives of subjects.

\section{What this paper contributes to our knowledge}

The Londrina ADL protocol was shown to be reproducible and valid when performed by physically independent adults age $\geq 50 \mathrm{y}$. In addition, the establishment of reference values for the protocol allows individual interpretation of the results. Therefore, a new assessment instrument of ADL that includes a broad spectrum of daily activities can now be used reliably in clinical and research settings.

\section{Methods}

\section{Study Design and Sample}

In a cross-sectional study, a convenience sample composed of 93 physically independent adults age $\geq 50$ y was recruited from a database of previous studies performed in our laboratory as well as relatives of students and employees of the university. The study was carried out from April 2014 to January 2016 at the Laboratory of Research in Respiratory Physiotherapy, State University of Londrina, Brazil. The study was approved by the institutional ethics committee (approval 048/2014), and all of the participants gave informed consent.

The inclusion criteria were: age $\geq 50$ y (to establish reference values of the Londrina ADL protocol in an age group that comprises patients with COPD), independence to perform ADL, and the absence of any severe and/or unstable disease that could limit the performance of the tests. Individuals were excluded if they were not able to complete all of the assessments. In addition to the Londrina ADL protocol, to study the validity of the protocol and to characterize the sample, all participants underwent additional assessments of lung function, anthropometric and demographic data, exercise capacity, functional capacity, physical activity in daily life, comorbidities, mental status and independence in daily activities. 


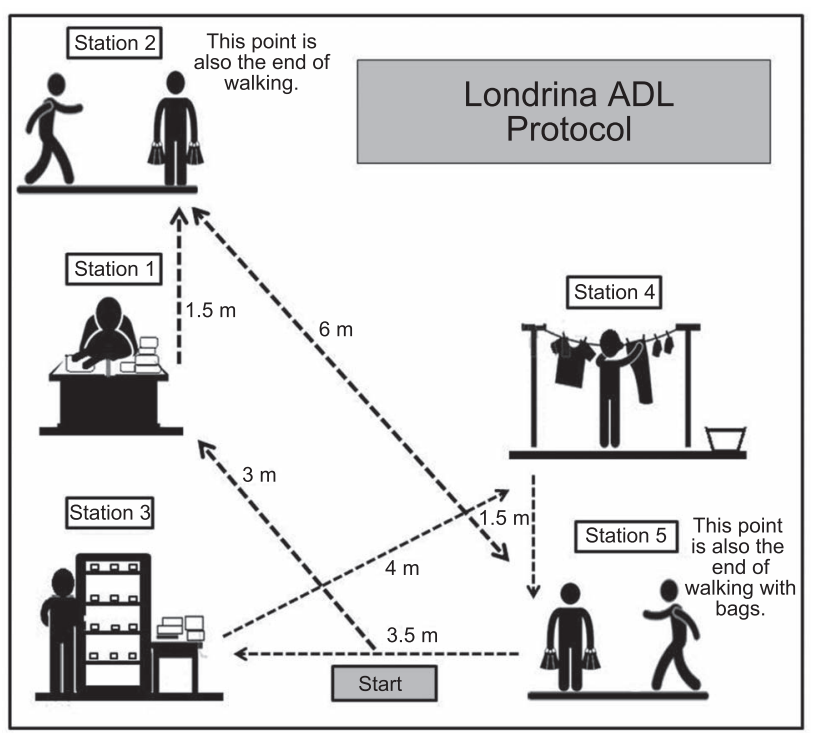

Fig. 1. Positioning of activity stations in the Londrina activities of daily living (ADL) protocol. The subject is initially positioned in the start area. He/she walks to station 1 to perform the established activity (objects on the table). Finishing activity 1 , the subject walks to station 2 (beginning of walking with bags), where he/she takes the 2 bags positioned on the floor, already containing the predetermined load, and begins walking, carrying one bag in each hand. This walking occurs in the 6-m line, 3 consecutive times. In other words, the subject walks to the end of the 6-m line, turns around, walks back to the first position, turns around, and walks once again to the end of the 6-m line, finalizing the activity on the point identified as the end of walking with bags (the same as station 5). At this point, the subject leaves the bags on the floor and walks to station 3 (shelves) to perform this activity. After this activity is concluded, the subject walks to station 4 (clothesline) and, after this activity is concluded, goes to station 5 (beginning of walking) to start walking again through the $6-\mathrm{m}$ line 3 consecutive times, this time without the bags. The protocol is finalized at the point identified as the end of walking. More details about the protocol can be found in the text.

\section{Assessments}

Activities of Daily Living. The Londrina ADL protocol is composed of 5 activities organized in stations inside a room (minimal dimensions: $6.5 \times 5.1 \mathrm{~m}$ ). The position of the activity stations and the distance between them are shown in Figure 1. The sequence of the stations is as follows.

(1) Objects on the table. The participant sits on a chair in front of a table (dimensions: $120 \mathrm{~cm}$ [length] $\times 60 \mathrm{~cm}$ [width]) with a line separating it into 2 halves (left and right). The table has 10 objects on it (4 objects of $250 \mathrm{~g}, 4$ objects of $500 \mathrm{~g}$, and 2 objects of $1 \mathrm{~kg}$ ), all together on the left half of the table. The subject takes the objects, one by one, with both hands, and puts them all on the right half of the table. After that, the subject returns all of the objects in the same way to the left side of the table again.
(2) Walking with bags. The subject walks over a 6-m line, 3 consecutive times (back and forth, totaling $18 \mathrm{~m}$ ), carrying 2 bags, one in each hand. Inside the bags there are loads representing $10 \%$ of subject's body weight $(5 \%$ in each bag).

(3) Shelves. The subject stands in front of 4 shelves, one above the other (distance between the floor and first shelf, $42 \mathrm{~cm}$; distance from one shelf to the next, $45 \mathrm{~cm}$ ), with a table next to them. On the table, there are 12 objects (4 objects of $250 \mathrm{~g}, 4$ objects of $500 \mathrm{~g}, 2$ objects of $1 \mathrm{~kg}$, and 2 objects of $2 \mathrm{~kg}$ ). The participant takes the objects, one by one, with both hands, and put them on the shelves (without predetermined order). The subject organizes the objects on the shelves in such a way that 3 objects are placed on each shelf. When all of the objects are placed on the shelves, the subject returns them in the same way to the table (without a predetermined order).

(4) Clothesline. The subject stands in front of a clothesline positioned at eye level. A basket containing 10 items of clothing (median weight of the items $=122 \mathrm{~g}$ [range $80-442 \mathrm{~g}]$ ) is placed on the ground next to the subject. The subject takes all items, one by one, with both hands and hangs them on the clothesline. After hanging all items of clothing, the subject returns them to inside the basket, taking them one by one and with both hands.

(5) Walking. The subject walks back and forth again on the same 6-m line described in activity 2, 3 consecutive times, but without carrying bags.

Participants were instructed to perform the 5 activities at their usual pace. Between the activity stations, the subject also walked at their usual pace. Before the beginning of the first Londrina ADL protocol, the evaluator demonstrated to the participant the activities of the protocol in the same order in which he/she should perform them. The instructions given to the participants were: "Perform these activities as if you were doing them at home in a typical day. You are allowed to stop to rest if you feel it is necessary. We will tell you which station will be the next at the end of each activity." No encouragement was given during the protocol.

The time spent to perform the Londrina ADL protocol was registered using a stopwatch, and it was used as the Londrina ADL protocol outcome. Other measurements before and after the Londrina ADL protocol included: blood pressure, heart rate, and sensation of dyspnea and fatigue (modified Borg scale). The Londrina ADL protocol was performed twice (by the same evaluator) on the same day with a 30-min interval between protocols.

Anthropometric and Demographic Data. Sex, age, and anthropometric variables (weight, height, and body mass index) were collected. ${ }^{11}$ 
Lung Function. Lung function was assessed by spirometry (Spiropalm, COSMED, Pavona di Albano, Italy) to exclude ventilatory impairments not related to the aging process. The test was performed according to the American Thoracic Society/European Respiratory Society guidelines, ${ }^{12}$ and the predicted values were calculated for the Brazilian population. ${ }^{13}$

Physical and Functional Capacity. Two 6-min walk tests (6MWTs) were performed according to the American Thoracic Society/European Respiratory Society guidelines, ${ }^{14}$ and the greater walked distance was considered for analysis. The reference values used were those described by Britto et al. ${ }^{15}$ The walk distance was used as the criterion variable to study the validity of the Londrina ADL protocol.

The 6-min pegboard and ring test was used to assess the arms' function. Two tests were performed as described by Zhan et al. ${ }^{16}$ Subjects were requested to move on a pegboard as many rings as possible within $6 \mathrm{~min}$. The outcome is the number of rings moved during the test.

The 30-s chair stand test evaluates lower-limb function. The test was performed according to Jones et al. ${ }^{4}$ Subjects were asked to stand up and sit down from a chair with their arms crossed over their chest as many times as possible within $30 \mathrm{~s}$. The outcome was the total number of stands executed during the test.

The timed up-and-go was used to assess mobility. The test was performed according to the standardization proposed by Podsiadlo et al. ${ }^{5}$ Participants were instructed to stand up from a chair, walk $3 \mathrm{~m}$ at their usual walking speed, turn around a cone, walk back to the chair, and sit down. The outcome is the time spent to perform the test.

The one-leg balance test was used to assess static balance. The test was performed according to the protocol proposed by Greene et al. ${ }^{17}$ The test consisted of the longest period (in seconds) that the subject could stand on one leg in a 30-s window. The test was performed 3 times, and the average time was used for analysis.

The level of physical activity in daily life was assessed for $7 \mathrm{~d}$ with a pedometer (SW-200 Digiwalker, Yamax, Tokyo, Japan). Subjects were instructed to wear the pedometer on the right side of the waist after waking up in the morning for $\geq 12 \mathrm{~h} / \mathrm{d}$. They were instructed to maintain their usual routine during the monitoring period. At the end of each assessment day, the individual had to register the number of steps in a daily log. The daily physical activity level was determined by the average of the 7 assessment days. ${ }^{18,19}$

Self-reported comorbidities and medications used were assessed by a questionnaire prepared by the authors.

The Mini Mental State Examination ${ }^{20}$ was used to assess cognitive function. Six cognitive domains were evaluated: time orientation, place orientation, registration, at- tention and calculation, recall, and language and visual construction. The score was adjusted for age and education level.

For independence in daily life, the Katz scale ${ }^{21}$ was applied to assess independence in basic activities, such as getting dressed, eating, or taking a shower. The score ranges from 0 to 6 points. Additionally, the Lawton-Brody scale 22 was used to evaluate independence in instrumental activities of daily living, such as managing medication and money, using a telephone, and going shopping. The score of this instrument ranges from 7 to 21 points.

\section{Sample Size Calculation}

The sample size calculation was performed taking into account a minimum correlation of 0.30 between the Londrina ADL protocol and anthropometric and demographic variables, an $\alpha$ value of .05 , power of $80 \%$, and $10 \%$ dropout rate. The number of subjects needed for this study was 93.

\section{Statistical Analysis}

The statistical analysis was performed using the statistical packages SPSS 20.0 (SPSS, Chicago, Illinois) and GraphPad Prism 6 (GraphPad Software, La Jolla, California). The normality of data distribution was evaluated using the Shapiro-Wilk test. The Wilcoxon test was used to compare the first and second Londrina ADL protocol. The intraclass correlation coefficient was used to determine the reproducibility of the Londrina ADL protocol, and a BlandAltman plot was built to visually assess the agreement between both protocols. Validity of the Londrina ADL protocol against the $6 \mathrm{MWT}$ was verified using the Pearson correlation coefficient. Correlations between the Londrina ADL protocol and other measurements, including anthropometric and demographic variables, were studied using the Pearson or Spearman coefficients. A multiple linear regression model was applied in which time spent to perform the Londrina ADL protocol was the dependent variable, and demographic and anthropometric data previously correlated to the Londrina ADL protocol were included as independent variables. To verify the reliability of the reference equation derived from the regression model, it was applied afterwards in a different group of physically independent adults, composed of 23 individuals recruited according to the same inclusion criteria of the present sample. The Spearman correlation coefficient was used to verify the correlation between the actual Londrina ADL protocol time and the predicted value. A Bland-Altman plot was also used to visualize agreement between the actual Londrina ADL protocol time and the predicted value. The level of statistical significance was set as $P \leq .05$. 
Table 1. Characteristics of the Participants

\begin{tabular}{|c|c|}
\hline Characteristics & Values \\
\hline Age, mean \pm SD y & $66 \pm 9$ \\
\hline \multicolumn{2}{|l|}{ Age, $n$} \\
\hline $50-59$ y & 28 \\
\hline $60-69 y$ & 30 \\
\hline $70-79 y$ & 27 \\
\hline$\geq 80 \mathrm{y}$ & 8 \\
\hline \multicolumn{2}{|l|}{ Age, male/female $(n=25 / 68), n$} \\
\hline $50-59$ у & $6 / 22$ \\
\hline $60-69$ y & $8 / 22$ \\
\hline $70-79 y$ & $10 / 17$ \\
\hline$\geq 80 \mathrm{y}$ & $1 / 7$ \\
\hline Height, mean $\pm \mathrm{SD} \mathrm{cm}$ & $157 \pm 9$ \\
\hline Weight, mean $\pm \mathrm{SD} \mathrm{kg}$ & $73 \pm 14$ \\
\hline BMI, mean $\pm \mathrm{SD} \mathrm{kg} / \mathrm{m}^{2}$ & $29 \pm 5$ \\
\hline $\mathrm{FEV}_{1} / \mathrm{FVC}$, median (IQR) & $0.81(0.78-0.83)$ \\
\hline $\mathrm{FEV}_{1}$, mean $\pm \mathrm{SD} \%$ predicted & $98 \pm 15$ \\
\hline $6 \mathrm{MWT}$, mean $\pm \mathrm{SD} \mathrm{m}$ & $531 \pm 78$ \\
\hline $6 \mathrm{MWT}$, median (IQR) $\%$ predicted & $104(99-113)$ \\
\hline 30-s chair stand test repetitions, median (IQR) & $11(10-13)$ \\
\hline $6 \mathrm{PBRT}$, mean $\pm \mathrm{SD}$ number of rings & $388 \pm 70$ \\
\hline TUG, median (IQR) s & $9(8-10)$ \\
\hline One-leg balance test, median (IQR) s & $24(12-30)$ \\
\hline Level of PADL, median (IQR) steps/d & $6,796(4,244-9,334)$ \\
\hline \multicolumn{2}{|l|}{ Level of PADL, $* n$} \\
\hline Sedentary $(<5,000$ steps/d $)$ & 30 \\
\hline Low activity $(5,000-7,499$ steps/d) & 22 \\
\hline Somewhat active $(7,500-9,999$ steps/d) & 20 \\
\hline Active $(10,000-12,499$ steps/d) & 17 \\
\hline Highly active $(>12,500$ steps/d) & 3 \\
\hline \multicolumn{2}{|l|}{$\begin{array}{l}\text { Independence in daily life, median (IQR) } \\
\text { points }\end{array}$} \\
\hline Katz scale & $6(6-6)$ \\
\hline Lawton and Brody & $21(21-21)$ \\
\hline Mini Mental State & $27(25-29)$ \\
\hline $\begin{array}{l}{ }^{*} \text { Classification proposed by Tudor-Locke et al. }{ }^{19} \\
N=93 . \\
\text { BMI }=\text { body mass index } \\
\text { IQR }=\text { interquartile range } \\
\text { 6MWT }=6 \text {-min walk test } \\
6 \text { PBRT }=6 \text {-min pegboard and ring test } \\
\text { TUG }=\text { timed up-and-go } \\
\text { PADL = physical activity in daily life }\end{array}$ & \\
\hline
\end{tabular}

\section{Results}

One hundred four physically independent adults were initially identified for possible enrollment. However, 11 subjects were excluded due to the following reasons: neurological $(n=4)$ and orthopedic $(n=7)$ impairment. Therefore, the final sample consisted of 93 subjects with ages ranging from 50 to $87 \mathrm{y}$. The characteristics of the subjects are described in Table 1 . The majority of subjects had on average 2 self-reported non-limiting comorbidities, including mild cardiac disease, arterial hypertension, pe-

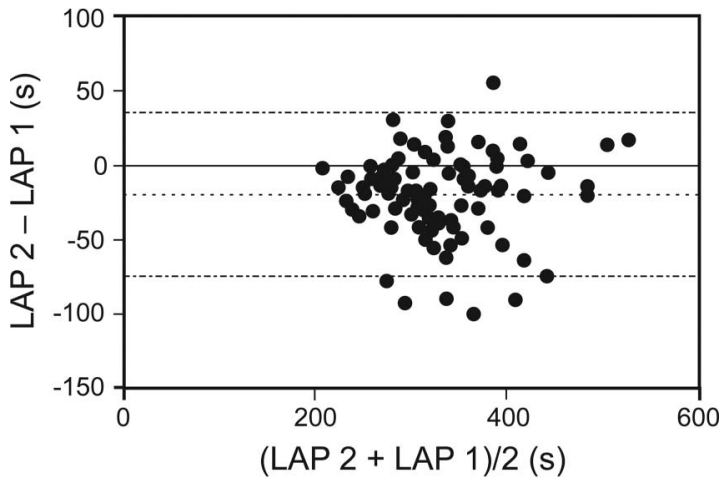

Fig. 2. Bland-Altman plot of the difference between the first Londrina activities of daily living protocol 1 (LAP 1) duration and the second test (LAP 2) plotted against the mean of LAP 1 and LAP 2. The center dotted line shows the mean, and upper and lower dotted lines denote the upper and lower limits, respectively.

ripheral vascular disease, diabetes mellitus, osteoporosis, osteoarthritis, and thyroid disease. In general, subjects presented normal cognitive function. All subjects were independent for basic activities and independent or partially independent to perform instrumental activities.

\section{Reproducibility of the Londrina ADL Protocol}

On average, subjects spent $339 \pm 64$ s (95\% CI $326-$ $353 \mathrm{~s})$ and $321 \pm 65 \mathrm{~s}(95 \% \mathrm{CI} 307-334 \mathrm{~s})$ to perform the first and second Londrina ADL protocol, respectively $(P<.001)$. There was a reduction of $18 \pm 28 \mathrm{~s}($ or $5.3 \%)$ in the second Londrina ADL protocol. Despite the difference between the Londrina ADL protocols, the protocol was highly reproducible (intraclass correlation coefficient $=0.91,95 \%$ CI 0.86-0.93, $P<.001)$. The BlandAltman plot showed good agreement between the first and second test (Fig. 2). Since the test was reproducible, further analyses in the study were performed always using as an outcome the first Londrina ADL protocol carried out.

\section{Validity of the Londrina ADL Protocol}

There was a moderate correlation between the Londrina ADL protocol and the 6-min walk distance $(\mathrm{r}=-0.53)$. The Londrina ADL protocol also presented weak to moderate correlations with other variables of functional capacity and level of physical activity in daily life, such as the 6-min pegboard and ring test $(r=-0.61), 30-\mathrm{s}$ chair stand test $(r=-0.33)$, timed up-and-go $(r=0.50)$, and the one-leg balance test $(\mathrm{r}=-0.41)$, as well as with the level of physical activity in daily life $(r=-0.29)$. There was no correlation between the time spent in the protocol and independence in daily life (Katz scale, $\mathrm{r}=-0.08$; Lawton and Brody, $\mathrm{r}=-0.18$; mental status, $\mathrm{r}=-0.22)$. 
Table 2. Linear Multiple Regression Analysis With the Londrina Activities of Daily Living Protocol as Dependent Variable

\begin{tabular}{lcccc}
\hline \hline & $\begin{array}{c}\text { Unstandardized } \\
\text { Coefficient (B) }\end{array}$ & 95\% CI for B & $P$ & $\begin{array}{c}\text { Part } \\
\text { Correlation }\end{array}$ \\
\hline Constant & 135.618 & -51.621 to 219.616 \\
Age (years) & 3.102 & -1.836 to 4.368 & $<.001$ & 0.45 \\
\multicolumn{5}{l}{$\begin{array}{l}\text { Residual standard }=57.65 \text { s. The derived equation from the regression analysis was: Londrina } \\
\text { activities of daily living protocol }\end{array}$ pred (seconds) $=135.618+(3.102 \times$ age [years]). } \\
\hline
\end{tabular}

Table 3. Londrina Activities of Daily Living Protocol Duration According to Each Age Group

\begin{tabular}{lcc}
\hline \hline Age $(\mathrm{y})$ & Time $(\mathrm{s})$ & $95 \%$ CI (s) \\
\hline $50-59$ & $304 \pm 51$ & $284-342$ \\
$60-69$ & $332 \pm 56$ & $312-353$ \\
$70-79$ & $366 \pm 64$ & $341-392$ \\
$\geq 80$ & $396 \pm 70$ & $338-455$ \\
& & \\
Results are mean \pm SD. & & \\
\hline
\end{tabular}

\section{Londrina ADL Protocol Determinants and Reference Equation}

There was significant correlation between the Londrina ADL protocol and age $(r=0.45)$, but there was no significant correlation with either weight $(\mathrm{r}=-0.17)$ or height $(\mathrm{r}=-0.17)$. A stepwise multiple regression model including age and sex as independent variables showed that only age explained the time spent to perform the Londrina ADL protocol $\left(\mathrm{r}^{2}=0.21, P<.001\right)$. Unstandardized coefficients, part correlation, and significance are shown in Table 2. The derived reference equation to predict reference values for the Londrina ADL protocol was: Londrina ADL protocol $l_{\text {pred }}(\mathrm{s})=135.618+(3.102 \times$ age [y]). In addition, a table containing the reference values for the Londrina ADL protocol in each age group is also provided (Table 3).

\section{Reliability of the Reference Equation}

The characteristics of the group composed of 23 physically independent adults ( 8 male) studied a posteriori were: age $=63 \pm 9 \mathrm{y}$, body mass index $=28 \pm 4 \mathrm{~kg} / \mathrm{m}^{2}$, and $\mathrm{FEV}_{1} / \mathrm{FVC}=0.81 \pm 0.03$. When the reference equation was applied to this group, there was no difference between the actual $(335 \pm 74 \mathrm{~s}, 95 \%$ CI $303-367 \mathrm{~s})$ and predicted Londrina ADL protocol (mean difference: 3 s [95\% CI -29 to $22 \mathrm{~s}$ ], $P=.78$ ). Furthermore, there was a moderate correlation between the actual and predicted Londrina ADL protocol ( $\mathrm{r}=0.70,95 \% \mathrm{CI} 0.41-0.86)$. The Bland-Altman plot (Fig. 3) shows the agreement between the actual and

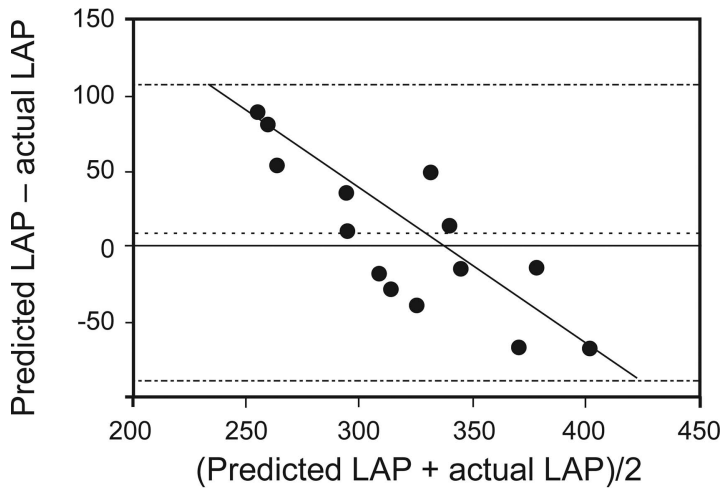

Fig. 3. Bland-Altman plot of the difference between the actual and predicted Londrina activities of daily living protocol (LAP) plotted against the mean of actual LAP and predicted LAP. The solid line represents the correlation of the mean with the difference between actual and predicted LAP $(r=-0.86)$. The center dotted line shows the mean, and upper and lower dotted lines denote the upper and lower limits, respectively.

predicted Londrina ADL protocol. There was strong correlation between the average of actual and predicted Londrina ADL protocol duration and the difference between actual and predicted Londrina ADL protocol duration $(\mathrm{r}=-0.86)$

\section{Discussion}

This study showed that the Londrina ADL protocol is reproducible when performed by physically independent adults age $\geq 50 \mathrm{y}$, showing a good test-retest agreement despite presenting a relatively small difference between the first and second performance (5.3\%). The Londrina ADL protocol correlated significantly with measures of functional exercise capacity (6MWT), lower and upper extremity function, mobility balance, and level of physical activity in daily life, supporting convergent validity for the measure. Furthermore, this study established an equation to predict values of the time spent to perform the protocol, using an easily obtainable variable (ie, the subject's age).

The Londrina ADL protocol was shown to be reproducible with a strong intraclass correlation coefficient value (0.91). Despite the small difference between the first and second Londrina ADL protocol (only 5.3\%), this is unlikely to have any clinical implications, since the effect size value was small $(0.28)$ as well. Moreover, a difference $<10 \%$ is considered acceptable when evaluating measurement instruments. For these reasons, only one Londrina ADL protocol is indicated when assessing physically independent adults $\geq 50 \mathrm{y}$ old. The good reproducibility of the protocol can be mainly attributed to 2 aspects: (1) the instructions on how to perform the protocol were standardized, and (2) the same evaluator conducted both tests. Hill et $\mathrm{al}^{23}$ found high agreement (intraclass correlation coef- 
ficient $=0.96)$ when the grocery shelving task was performed twice by subjects with COPD. Jones et $\mathrm{al}^{4}$ also found a good test-retest agreement between the first and the second sit-to-stand test performed by subjects with COPD, indicating that only one test is required.

The study of the construct validity of the Londrina ADL protocol was a challenge, since there is no accepted standard to assess ADL. We used the 6MWT as criterion outcome because it measures functional capacity, which is necessary to perform ADL. There was a moderate correlation between the Londrina ADL protocol and functional capacity, demonstrating that the Londrina ADL protocol is a valid protocol. It is possible that a stronger correlation was not found due to the fact that functional capacity is only one of the components necessary to perform ADL. In addition, the 6MWT involves more lower-limb activity, whereas the Londrina ADL protocol consists of activities of both the upper and lower limbs. The same reasoning can explain the moderate correlation found between the Londrina ADL protocol and the 6-min pegboard and ring test. Contrasting with the present results, Skumlien et $\mathrm{al}^{3} \mathrm{dem}-$ onstrated that the Glittre ADL protocol was highly correlated with the 6MWT in subjects with COPD. This result occurred probably because the subjects were instructed to perform the protocol as fast as possible, as in the 6MWT. On the other hand, in the Londrina ADL protocol, subjects were instructed to performed the test at a normal (ie, usual) pace.

The Londrina ADL protocol correlated moderately or weakly with upper- and lower-limb function, mobility, balance, and level of physical activity in daily life. A limited correlation was also expected, since these variables again represent separately some components involved in the performance of ADL. It is important to reinforce that the Londrina ADL protocol includes activities that involve both upper and lower limbs (walking, walking with bags, sitting and standing, turning around), requiring abilities such as balance, mobility, and muscle strength during the entire protocol. Takeda et $\mathrm{al}^{24}$ found a moderate correlation between arm exercise capacity (6-min pegboard and ring test) and ADL measured by a questionnaire. In the present study, the level of physical activity in daily life was the variable that presented the weakest correlation with the Londrina ADL protocol $(r=-0.29)$. A possible explanation for this finding is that the physical activity in daily life measurement used in the analysis was step counting with the use of a pedometer. Besides the fact that steps/d represent an activity predominantly involving the lower limbs, it is well known that the accuracy of pedometers decreases with slower walking speeds due to increased age and body mass index, ${ }^{25}$ which are characteristics of the subjects in our sample.

Approximately $20 \%$ of the variability of the time spent to perform the Londrina ADL protocol was only explained by age. This finding is in accordance with previous stud- ies, which demonstrated that the advance toward aging is related to decreases in muscle strength, mobility, and balance, which contribute to impairment in the performance of ADL. ${ }^{26}$ The anthropometric variables analyzed did not influence the time spent in the Londrina ADL protocol. This finding can possibly be explained by the fact that height and weight interfere more in capacity than in performance tests, as was seen in the 6MWT, for instance. Finally, the time spent in the Londrina ADL protocol was not influenced by sex. Despite the protocol including activities that are more common to women's routine due to the presence of domestic tasks, men can perform similar movements, during work activities. Teixeira et $\mathrm{al}^{27}$ showed that there was no difference in time spent walking per day between women and men $>60$ y old, corroborating the present findings.

Functionality in the elderly is influenced by age, social class, income, education, health conditions, cognition, environment, life history, and personality features, ${ }^{28}$ in addition to other physical characteristics, such as muscle strength, low level of physical activity, and slow gait. ${ }^{29}$ It is known that frailty is associated with functionality and other factors, such as multiple health problems, fatigue, hearing, vision, cognition, and psychological disturbances (depression and anxiety). ${ }^{30}$ It can be hypothesized that these factors could explain at least part of the $79 \%$ remaining to be explained.

Regarding the reference equation for the Londrina ADL protocol, despite its modest coefficient of determination $\left(\mathrm{r}^{2}=0.21\right)$, it was reliable when applied a posteriori. It is important to determine the reference values for clinical tests to facilitate the interpretation of results, because they allow comparisons between results and expected values. Tests such as the short physical performance battery, ${ }^{31}$ senior fitness test, ${ }^{32}$ and American Alliance for Health, Physical Education, Recreation, and Dance battery test ${ }^{33}$ have normative values, facilitating their interpretation in both research and clinical practice.

This study has some limitations. First, it involves a convenience sample, which may limit its representativeness, although we strove to recruit subjects with similar characteristics of the studied population (ie, adults age $\geq 50 \mathrm{y}$ ). Second, the use of pedometers limited the assessment of physical activity in daily life; however, this instrument was chosen due to logistic reasons. Furthermore, the new protocol requires some physical space (maximum distance required: $6 \mathrm{~m}$ ) and objects to be applied, which may not be available in clinical settings. On the other hand, the objects used in the protocol are simple and easily obtained, since they must not have an exact size or weight; in addition, the objects can be displayed in a clinical or hospital room where is possible to walk $6 \mathrm{~m}$. Last, the Londrina ADL protocol takes, on average, $5 \mathrm{~min}$ to be performed, being slightly longer than some functional tests previously proposed. How- 
ever, the authors opted for a longer protocol where the subjects could perform the activities at their usual pace instead of at maximal speed, reflecting better functionality.

\section{Conclusions}

In general, the Londrina ADL protocol was reproducible and valid when assessing ADL in apparently healthy adults $\geq 50$ y old. A reference equation for the Londrina ADL protocol was established, including as an independent variable only age $\left(r^{2}=0.21\right)$. Therewith, a new assessment instrument of ADL that includes a broad spectrum of daily activities is now available to be used in clinical and research settings when evaluating adults $\geq 50$ y old. Moreover, only one test is necessary to assess the performance of ADL using the Londrina ADL protocol. In addition, the establishment of reference values for the protocol allows individual interpretation of the results reached by the assessed subject.

\section{ACKNOWLEDGMENTS}

We acknowledge the support of Companha de Aperfeiçoamento de Pessoal de Nível Superior (CAPES) and Conselho Nacional de Desenvolvimento Científico e Tecnológico ( $\mathrm{CNPq}$ ), Brazil. In addition, we are grateful to colleagues at the Laboratory of Research in Respiratory Physiotherapy for contributions to this study.

\section{REFERENCES}

1. Meijer EP, Westerterp KR, Verstappen FT. Effect of exercise training on total daily physical activity in elderly humans. Eur J Appl Physiol Occup Physiol 1999;80(1):16-21.

2. Paterson DH, Jones GR, Rice CL. Ageing and physical activity: evidence to develop exercise recommendations for older adults. Can J Public Health. 2007;98(Suppl 2):S69-S108.

3. Skumlien S, Hagelund T, Bjørtuft O, Ryg MS. A field test of functional status as performance of activities of daily living in COPD patients. Respir Med 2006;100(2):316-323.

4. Jones CJ, Rikli RE, Beam WC. A 30-s chair-stand test as a measure of lower body strength in community-residing older adults. Res Q Exerc Sport 1999;70(2):113-119.

5. Podsiadlo D, Richardson S. The timed "Up \& Go": a test of basic functional mobility for frail elderly persons. J Am Geriatr Soc 1991; 39(2):142-148.

6. Penninx BW, Ferrucci L, Leveille SG, Rantanen T, Pahor M, Guralnik JM. Lower extremity performance in nondisabled older persons as a predictor of subsequent hospitalization. J Gerontol A Biol Sci Med Sci 2000;55(11):M691-M697.

7. Guralnik JM, Simonsick EM, Ferrucci L, Glynn RJ, Berkman LF, Blazer DG, et al. A short physical performance battery assessing lower extremity function: association with self-reported disability and prediction of mortality and nursing home admission. J Gerontol 1994;49(2):M85-M94.

8. Guralnik JM, Winograd CH. Physical performance measures in the assessment of older persons. Aging 1994;6(5):303-305.

9. Rikli RE, Jones CJ. Development and validation of criterion-referenced clinically relevant fitness standards for maintaining physical independence in later years. Gerontologist 2013;53(2):255-267.
10. Reuben DB, Siu AL. An objective measure of physical function of elderly outpatients. The physical performance test. J Am Geriatr Soc 1990;38(10):1105-1112.

11. Gordon CC, Chumlea WC, Roche AF. Stature, recumbent length, and weight. In: Lohman TG, Roche AF, Martorell R, editors. Anthropometric standardization reference manual. Champaign, Illinois: Human Kinetics; 1988:3-8.

12. Miller MR, Hankinson J, Brusasco V, Burgos F, Casaburi R, Coates A, et al. Standardisation of spirometry. Eur Respir J 2005;26(2):319338.

13. Pereira CA, Sato T, Rodrigues SC. New reference values for forced spirometry in white adults in Brazil. J Bras Pneumol 2007;33(4): 397-406.

14. Holland AE, Spruit MA, Troosters T, Puhan MA, Pepin V, Saey D, et al. An official European Respiratory Society/American Thoracic Society technical standard: field walking tests in chronic respiratory disease. Eur Respir J 2014;44(6):1428-1446.

15. Britto RR, Probst VS, de Andrade AF, Samora GA, Hernandes NA, Marinho PE, et al. Reference equations for the six-minute walk distance based on a Brazilian multicenter study. Braz J Phys Ther 2013;17(6):556-563.

16. Zhan S, Cerny FJ, Gibbons WJ, Mador MJ, Wu YW. Development of an unsupported arm exercise test in patients with chronic obstructive pulmonary disease. J Cardiopulm Rehabil 2006;26(3):180-187; discussion 188-190.

17. Greene LS, Williams HG, Macera CA, Carterr JS. Identifying dimensions of physical (motor) functional capacity in healthy older adults. J Aging Health 1993;5(2):163-178.

18. Tudor-Locke C, Leonardi C, Johnson WD, Katzmarzyk PT, Church TS. Accelerometer steps/day translation of moderate-to-vigorous activity. Prev Med 2011;53(1):31-33.

19. Tudor-Locke C, Bassett DR Jr. How many steps/day are enough? Preliminary pedometer indices for public health. Sports Med 2004; 34(1):1-8.

20. Folstein MF, Folstein SE, McHugh PR. "Mini-mental state": a practical method for grading the cognitive state of patients for the clinician. J Psychiatr Res. 1975;12(3):189-198.

21. Lino VT, Pereira SR, Camacho LA, Ribeiro Filho ST, Buksman S. [Cross-cultural adaptation of the independence in activities of daily living index (Katz index)]. Cad Saude Publica 2008;24(1):103-112.

22. Santos RL, Virtuoso Júnior JS. Confiabilidade da versão brasileira da escala de atividades instrumentais da vida diária. RBPS 2008; 21(4):290-296.

23. Hill CJ, Denehy L, Holland AE, McDonald CF. Measurement of functional activity in chronic obstructive pulmonary disease: the grocery shelving task. J Cardiopulm Rehabil Prev 2008;28(6):402-409.

24. Takeda K, Kawasaki Y, Yoshida K, Nishida Y, Harada T, Yamaguchi $\mathrm{K}$, et al. The 6-minute pegboard and ring test is correlated with upper extremity activity of daily living in chronic obstructive pulmonary disease. Int J Chron Obstruct Pulmon Dis 2013;8:347-351.

25. Melanson EL, Knoll JR, Bell ML, Donahoo WT, Hill JO, Nysse LJ, et al. Commercially available pedometers: considerations for accurate step counting. Prev Med 2004;39(2):361-368.

26. Tudor-Locke C, Schuna JM Jr, Barreira TV, Mire EF, Broyles ST, Katzmarzyk PT, Johnson WD. Normative steps/day values for older adults: NHANES 2005-2006. J Gerontol A Biol Sci Med Sci 2013; 68(11):1426-1432.

27. Teixeira DC, Probst VS, Ramos EMC, Brunetto AF, Pitta F. Profile of physical activity in daily life in physically independent elderly men and women. Rev Bras Educ Fís Esporte 2012;26(4):645-655.

28. Neri AL. Qualidade de vida na velhice: enfoque multidisciplinar. In: Qualidade de vida na velhice e subjetividade, 1st edition. São Paulo: Alínea; 2007:151-171. 
29. Fried LP, Tangen CM, Walston J, Newman AB, Hirsch C, Gottdiener $\mathrm{J}$, et al. Frailty in older adults: evidence for a phenotype. $\mathrm{J}$ Gerontol A Biol Sci Med Sci 2001;56(3):M146-M156.

30. Schuurmans H, Steverink N, Lindenberg S, Frieswijk N, Slaets JP. Old or frail: what tells us more? J Gerontol A Biol Sci Med Sci 2004;59(9):M962-M965.

31. Volpato S, Cavalieri M, Sioulis F, Guerra G, Maraldi C, Zuliani G, et al. Predictive value of the short physical performance battery following hospitalization in older patients. J Gerontol A Biol Sci Med Sci 2011;66(1):89-96.

32. Mazo GZ, Petreça DR, Sandreschi PF, Benedetti TRB. Valores normativos da aptidão física para idosas brasileiras de 60 a 69 anos de idade. Rev Bras Med Esporte 2015;21(4):318-322.

33. Benedetti TRB, Mazo GZ, Gonçalves LHT. Bateria de testes da AAHPERD: adaptação para idosos institucionalizados. Rev Bras Cineantropom Desempenho Hum 2014;16(1):1-14.

This article is approved for Continuing Respiratory Care Education credit. For information and to obtain your CRCE

(free to AARC members) visit

www.rcjournal.com 